\section{Leaked CNRS report raises fears and hopes on job security}

[PARIS] A leaked report has heightened tensions between researchers at the French Centre National de la Recherche Scientifique (CNRS) and the ministry of national education, research and technology.

The draft assessment of CNRS was leaked to the newspaper Le Monde last week. It was written by the chair of an external visiting committee, the eminent French biologist Pierre Chambon; other members of the panel include David Baltimore, president of the California Institute of Technology, and Sir Ronald Oxburgh, rector of London's Imperial College of Science, Technology and Medicine.

Its contents have been reported as questioning the lifelong job security enjoyed by CNRS researchers. Many scientists are already suspicious that planned reforms by the ministry will result in the agency being dismantled (see Nature 396, 607; 1998).

Chambon has been quick to play down the conclusions of the report, arguing that it is only a "working document" that contained no radical new insights beyond the widely acknowledged lack of mobility in the French research system and the difficulties faced by young researchers in setting up independent

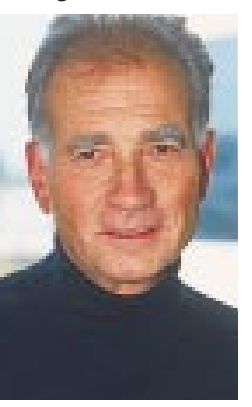

Chambon: draft was 'a working document'. whose time allocated to research and teaching duties would vary during their career according to their productivity.

Meanwhile, several members of the committee are said to be annoyed that Chambon circulated a draft they had not approved. Although members commented on a first draft, they had not seen the circulated version taking these comments into account. Chambon says the new draft was not intended to be published or made public, but was sent to CNRS and the ministry to test whether it was likely to be acceptable.

Oxburgh, who confirms that he had not seen the draft, says, "CNRS is an organization with a tremendous tradition and has produced some outstanding science. They have the problems inherent in any organization that appoints people for life for the sole purpose of doing research." Declan Butler

\title{
Japanese labs balk at bid to boost external evaluation
}

[TOKYO] Government-led efforts to promote the external evaluation of research in Japanese government institutes and national universities are meeting resistance from the laboratories themselves.

The first report on Japan's research evaluation system concludes that only a third of evaluations at research institutes run by science-related ministries are carried out by external assessors. The Science and Technology Agency (STA) report, released last week, says external evaluations are also uncommon in universities.

The need for greater evaluation was emphasized in guidelines drawn up in 1996 as part of the Science and Technology Basic Plan, which aims to double Japan's science spending by 2001 .

The guidelines, which also apply to individual projects, say that to be effective, they should be applied by an external review system. Although voluntary, they give a framework by suggesting timing, method and objectives. They also call for the results of evaluations to be made public, and for funding to be based on these.

An STA spokesman says that, as well as assessing the quality of research, evaluations are necessary to determine whether research is meeting social and economic needs, such as the creation of new industries. "It is important to find the priority areas for limited government funds, and to gain public support for our large investment in science and technology," he says.

The guidelines do not apply to universities, on the grounds that the independence of research and the balance between education and research must be respected. A separate 1996 proposal from the Council on University Education - an advisory body to the Ministry of Education, Science, Sports and Culture (Monbusho) - emphasized selfevaluation and in-house assessment of university research, but limits external evaluation to large projects.

According to the report, all but one of Japan's 98 national universities, and 381 out of all 587 Japanese universities are carrying out some form of research evaluation. But only a handful, such as Tokyo University's Research Centre for Advanced Science and Technology (RCAST), use external reviewers, and most of the results are confidential.

This contrasts with the National Research Institutes for Joint University Use, which provide facilities and equipment for domestic and international researchers, such as the High Energy Accelerator Research Organization in Tsukuba and the National Institute for Genetics (NIG). Eighty per cent of these have introduced external evaluation and have made the results public.

"University researchers are becoming increasingly aware of the importance of research evaluation, and many see it as a way of demonstrating the quality and accountability of their research," says Yoshiki Hotta, director of NIG and formerly director of Tokyo University's Genetics Research Laboratory. "But it may still take some time for the universities to fully adapt to the system."

Hotta emphasizes the importance of evaluation in improving prospects for young researchers. He plans to use evaluation at NIG to get rid of incompetent researchers and to introduce postdoctoral researchers.

Many argue that the lifetime tenure system that plagues Japanese universities with bureaucratic and conservative values can only be eradicated by external reviews. The system has long been criticized for inhibiting competitiveness at Japanese universities.

Some researchers say the main difficulty is the lack of a single framework. "External evaluations are carried out independently by departments and laboratories within the university, so the criteria of evaluations differ from one research group to another," says Etsuo Niki, director of RCAST.

Universities are under pressure to reform following a proposal to turn all 98 national universities into semi-autonomous institutions (see Nature 395, 730; 1998). Although strong resistance from universities and Monbusho meant that the proposal was omitted from the final version of the government's 1997 administrative reform plan, it resurfaced after last year's appointment of prime minister Keizo Obuchi.

Despite Obuchi's determination to reorganize Japan's administration, the plan continues to meet opposition from leading academics, such as Leo Esaki, the Nobel prizewinner and former president of Tsukuba University, who has claimed that it "will only make things chaotic".

But the strongest opposition comes from Akito Arima, the education minister and recently appointed director-general of STA, who has declared that such changes will be detrimental to research and education, as universities do not have the capacity to manage their increased autonomy.

In a bid to resist the government's plans on autonomy, the Council on University Education, chaired by Arima, plans to set up an independent body to assess national universities. Ironically, as president of Tokyo University in 1993, Arima introduced external review to the physics department (see Nature 362, 387; 1993).
AsakoSaegusa 